\title{
Reliability of technological systems of building construction in permanent EPS formwork
}

\author{
Makhmud Kharun *, Alexander P. Svintsov
}

Department of Civil Engineering, RUDN University, Moscow, Russia

\section{A RT ICLE INFO}

\section{Article history:}

Received 10 February 2017

Received in revised form

10 September 2017

Accepted 11 September 2017

\section{Keywords:}

Permanent EPS formwork

Quality parameters

Structural defect

Reliability

\begin{abstract}
A B S T R A C T
Technological system (TS) of cast-in-situ reinforced concrete (RC) building construction in permanent EPS formwork is one of the most effective and promising areas of contemporary construction. It is important to determine the level of reliability to improve the efficiency of TS and the quality of construction output. Experience shows that technological defects occur during the construction of RC structures in the permanent EPS formwork. In this regard, reliability assessment of TS on the quality parameters is the relevant. Estimation features of the reliability indices of construction TS is that it can be described mathematically based on the distribution law of observations data. In our study we used the following methods: visual inspection of structures and detection of technological defects; direct measurement of the size of deviations from the design values; statistical analysis of the measurement results; analysis of the qualitative characteristics of constructed structures by the quantitative parameters based on the theory of reliability of TS. It is established that the structural defects in permanent EPS formwork occur during the construction of cast-insitu RC buildings, and those are formed as the panels divergence under the thrust from fresh concrete mix. As a result, the thermal insulation layer of structures reduces, which may lead to the freezing in these parts. Based on the analysis of field measurements and generalizations of statistical data, the values of formation frequency of structural defects are determined, and also the assessment of assignment probability on quality parameters is given.
\end{abstract}

(c) 2017 The Authors. Published by IASE. This is an open access article under the CC BY-NC-ND license (http://creativecommons.org/licenses/by-nc-nd/4.0/).

\section{Introduction}

One of the most important trends of using the energy-saving technologies in construction is the building construction in permanent EPS formwork, panels of which are the thermal insulating and sound absorbing elements of structures simultaneously. Along with the mentioned features of this TS, the reliability on quality parameters represents a very important indicator.

Currently, the scientific periodicals present various aspects of the study of TS of cast-in-situ RC building construction in permanent EPS formwork. However, its reliability, including on quality indicators, dropped out of interests of researchers. It restrains the possibility of solving problems for improving the technological system to improve the quality of construction output.

\section{* Corresponding Author.}

Email Address: miharun@yandex.ru (M. Kharun) https://doi.org/10.21833/ijaas.2017.011.014

2313-626X/C 2017 The Authors. Published by IASE.

This is an open access article under the CC BY-NC-ND license

(http://creativecommons.org/licenses/by-nc-nd/4.0/)
As a result of full-scale investigation we established the causal links of occurrence of defects in structures which constructed in the permanent EPS formwork, as well as an assessment of the reliability of TS on quality parameters.

\section{Analysis of the stated issue}

One of the most efficient and modern construction technologies is the construction of buildings in the permanent formwork. In accordance with the features of constructed structures, facing panels, reinforced panels, wood-concrete panels, magnetite panels, polystyrene plates, etc. are used as permanent formwork (Verbruggen et al., 2013, 2014; VanderWerf, 2007). The use of permanent formwork for the construction of RC structures allows increasing their load-bearing capacity and significantly reducing the labor input (Scott et al., 2016; Havez et al., 2016). It is believed that a significant advantage of this TS is the minimum requirement of equipment for installation of formwork. One of the most significant disadvantages of this TS is the complexity of installation and 
alignment of formwork and also the lack of technical equipment for reliable temporary fixing of panels.

In the construction of residential buildings, permanent formwork, made in the form of blocks, consisting of EPS plates, interconnected by crosspieces, is widely used, that serves as thermal insulation of enclosing structures (Badin, 2012). The thickness of EPS plate is usually from 50 to $100 \mathrm{~mm}$ depending on the required thermal resistance. The distance between the inner surfaces of formwork plates is determined by the calculated design and usually is from 100 to $200 \mathrm{~mm}$. The use of permanent formwork assumes cast-in-situ construction of various buildings. Study of Ryazanova and Kamburg (2010) shows that the castin-situ construction in permanent EPS formwork has some advantages compared to other technologies: energy intensity of production is lower by an average of $30 \%$ compared to precast construction; low $(60 \%)$ capital investment in production base etc.

Building construction in permanent EPS formwork can solve the tasks of energy-saving in the process of their exploitation and create conditions for the design values of temperature and humidity conditions in the premises. Fedyuk and Baranov (2015) and Derome and Saneinejad (2010) presented the results of study of humidity characteristics of RC walls with permanent EPS formwork. It is noted that the initial humidity of EPS formwork depends on the implementation conditions of construction and finishing works, as well as on the content of completed houses until their occupancy. It was established that the microclimatic conditions match with regulatory requirements in the premises of buildings which built of RC in permanent EPS formwork.

Duration of humidification affects significantly on water absorption of EPS. According to Ralston and Osswald (2008), long humidifying (about one year) of unpressed EPS increases its humidity in 2-3 times.

In general, TS of cast-in-situ RC building construction in permanent EPS formwork is effective in technical and economic aspects. Technical and economic efficiency of EPS formwork, as noted by Badin (2012), allows us to consider this technology promising for contemporary construction.

The implementation of any construction technology is influenced by many and often uncontrollable factors that affect the parameters of expended resources, productivity and quality of construction output. A systematic monitoring of compliance with design solutions is carried out during building construction. Despite the strict quality control to completely eliminate the occurrence of defect is not possible. In this regard, improving the reliability of TS in terms of assignments on quality parameters is the relevant scientific and technical task.

Analysis of the current research suggests that in total defects that increase the risk of incidents in buildings and structures the human mistakes represent a significant part. About the significant responsibility of production personnel on reliability of TS and quality of construction output is noted by Svintsov and Panin (2011). In cast-in-situ RC building construction in permanent EPS formwork one of the most commonly occurring defects is disrupt of geometric parameters of walls in transverse direction (thrust). Being a significant, but not critical, the said form of defect can cause to the possible formation of thermal passages. These local defects are one of the major reasons for the downswing of comfort of building. In the places of formation of such defects the thickness of thermal insulation layer may be reduced. In this regard, the construction output, quality of which should meet the contemporary requirements, is possible only on the basis of total quality management. One of the most important quality control of construction output is the establishment of science-based criteria of objective assessment of the reliability of TS.

Study of Baiburin and Golovnev (2006) showed that the defects, which occur during the execution of construction work, are the main cause of about $60 \%$ of accidents in the construction industry. Baiburin (2015) revealed in the analysis of causal links of occurrence of accidents due to the construction defect that the relationship between the theoretical and the actual probability of accident in buildings and structures leads to the increased actual risk over the theoretical value by ten times. Presented analysis methods of reliability of TS allow quantifying of the assignment on the quality parameters of construction output. However, issues on the assessment of reliability indexes of TS in the cast-insitu construction in permanent EPS formwork remained outside these publications.

Assessment features of reliability indexes of TS are presented by Abramyan et al. (2014), which consist in the fact that the safety of construction, especially linearly extended projects, can be mathematically described using the Poisson distribution. One of the most effective methods of increasing the reliability of TS is the organization of rhythmic work with the exception of losses and delays at unexpected failures.

Assessment concept of construction technology in the aspect of its sustainability is presented by Nazarko (2015). This paper presents the principles, stages and methods of technology assessment, which are applicable in the process of achieving the sustainability in the construction industry. Nightingale (2004) presented the empirical models of probabilistic processes in the functioning of TS. It is shown that there is a significant economic link between the scientific recommendations and the functioning of TS.

To improve the efficiency of control over the implementation of technological processes in construction, it is suggested to automate the collection and the analysis of data using the computer technology with appropriate software (Soltani et al., 2016). Test results of the presented system allowed the authors to reduce the time for data analysis, and simultaneously increase the 
accuracy of detection of defects as compared to traditional methods.

Analysis of information sources on the essentially of presented study shows that TS of cast-in-situ RC building construction in permanent EPS formwork is the solution of one of the most important tasks to improve the energetic and economic efficiency of contemporary construction. However, currently, the existing methods for assessing its reliability are not studied enough. It restrains the solution of tasks of quality assurance of construction output to the present principles of quality management concepts specified in ISO 9000.

\section{Methods of study and analysis}

In our study we used the following methods: visual inspection of structures and detection of technological defects; direct measurement of the size of deviations from the design values; statistical analysis of the measurement results; analysis of the qualitative characteristics of constructed structures by the quantitative parameters based on the theory of reliability of TS.

Technological defects of cast-in-situ RC structures, built in the permanent EPS formwork, revealed during the visual inspection (Fig. 1).

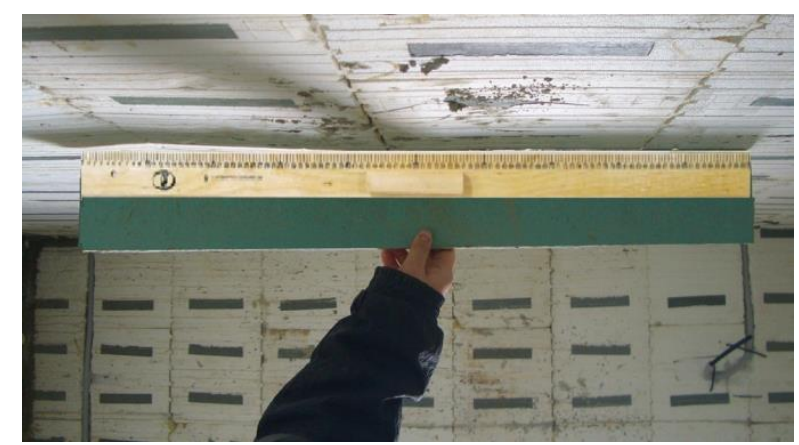

Fig. 1: Identified deviation of ceiling surface from the design position

Mathematical analysis of measurements was made by known methods of statistical analysis. It allowed us to obtain the values of defected areas with the reliability of $\gamma=0.90$. The values of the total surface area of walls and ceilings were accepted according to the design documentation.

The statistically significant data of defects and design values of surface area of constructed structures was used to assess the reliability of TS on quality parameters.

Construction TS is a set of functionally related technological equipment, items of production, production and management personnel, which are designated to perform in the regulated conditions of production operations and technological processes for the production and implementation of construction output.

One of the most important indexes of reliability of TS is the probability of assignment on quality parameters. Reliability assessment on quality parameters is carried out with the following criteria: -mismatch of one of the indicators of quality of construction output with the requirements of design and normative documentation;

- mismatch of parameters or implementation modes of operations or construction process diagram;

- mismatch of controllable parameters of operations and construction process to the norms, and regulated design and regulatory documentation.

It is important to note that only the parameters, which are not appropriate to the level of regulated design and regulatory documentation, should be taken for the failure criterion when assessing the reliability of quality parameters of construction output.

In accordance with the Russian GOST 27.203-83 the probability of assignment on quality parameters is determined by Eq. 1:

$P_{w j}(T)=P\left\{W_{j} \leq W_{o j}\right\}$

where $W_{j}, W_{0 j}$ - actual and allowable rate of the detected defects in a batch at the $j$-th parameter accordingly. Rate of the detected defects is determined by Eq. 2:

$W=\frac{d(T)}{N(T)}$

where $d(T)$ - number of defects in the product batch; $N(T)$ - the total number of products in a batch that manufactured for an operating time $T$.

Operating time $T$ can be measured in units of time, cycles of operation or unit of manufactured products.

Study was performed on the basis of single sampling method on the defective level. The allowable rate of detected defects is accepted $W_{0}=$ 0.02 . The minimum value of probability of assignment on quality parameters (guaranteed value of the probability of failure-free operation) is accepted $P_{\beta}=0.90$. Reliability analysis of the TS in terms of the quality of cast-in-situ RC structures that constructed in permanent EPS formwork allowed us to obtain the statistically significant results of the distribution of detected defects and to determine the reliability of quality criteria in ensuring of $\gamma \geq 0.90$.

\section{Results and discussion}

Construction technology of cast-in-situ RC structures in permanent EPS formwork is characterized by a relative novelty for the construction in Russia. One of the features of building construction in permanent EPS formwork is that the permanent EPS formwork serves simultaneously as a thermal insulator and a sound absorber. Different types of permanent EPS formwork are presented in the Russian construction market (Abramyan et al., 2014).

Due to the high thermal-insulating properties of EPS the buildings erected in permanent EPS formwork characterized by high thermal efficiency. 
Due to the fact that the enclosing structures of buildings must have the thermal resistance that meets the regulatory requirements of thermal protection of buildings and their quality must be monitored regularly. Quality control of construction output is mandatory, since the implementation of any construction technology may cause defects. Fig. 2 shows a fragment of wall with defects caused by the thrust and divergence of formwork panels.

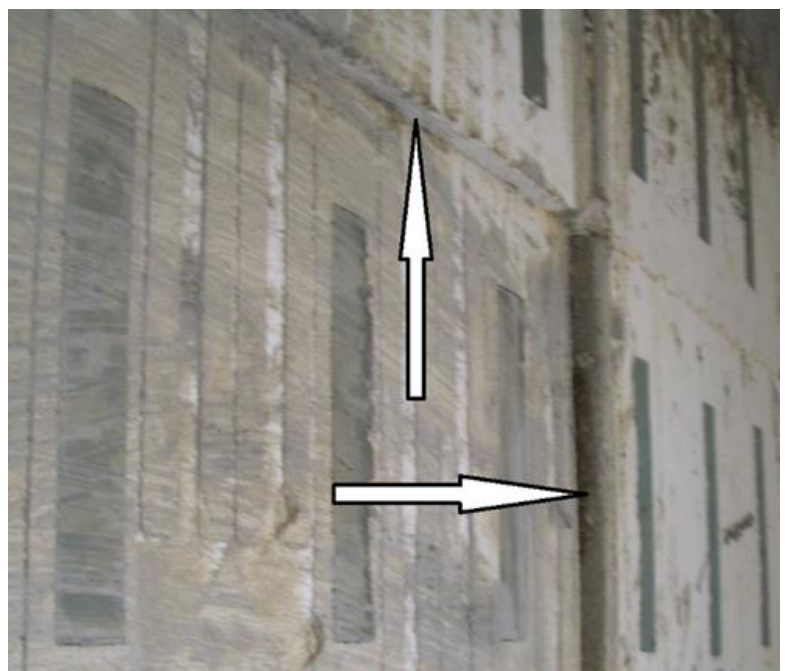

Fig. 2: Exterior damage of a cast-in-situ RC wall in permanent EPS formwork

Such defect is not critical, but is subject to mandatory resolve. The divergence of formwork panels due to the increase of thickness of RC wall and causes a decrease in thickness of thermalinsulation layer of EPS. Decrease of thermalinsulating layer is associated with the possibility of freezing of wall in winter. To resolve the defects, it is necessary to cut off a significant portion of EPS formwork with the need for designed vertical position of wall without anomalous irregularities. Fig. 3 shows a fragment of wall with the removed layer of EPS formwork.

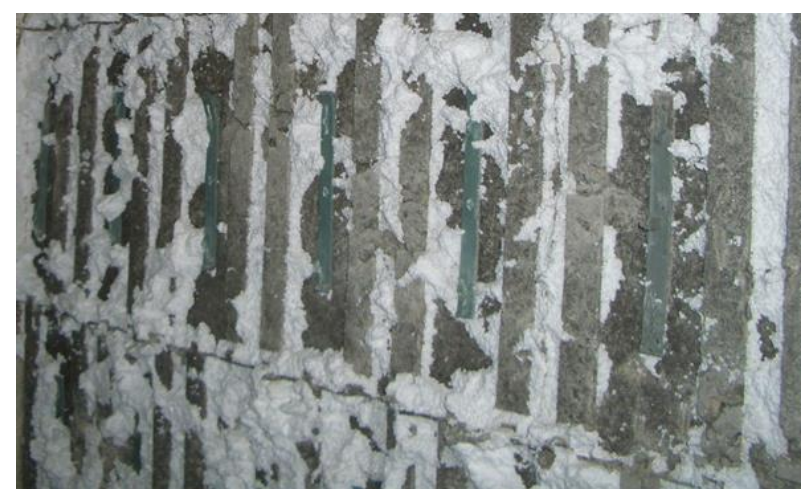

Fig. 3: Fragment of a wall with the removed layer of EPS formwork

Resolving of such defects increases the cost of construction output. In this regard, it seems appropriate to carry out an analysis of defects to identify the causal links, as well as to assess the operational reliability of TS, which will allow offering some activities for its improvement. Fig. 4 shows a fragment of outer wall, prepared for finishing work.

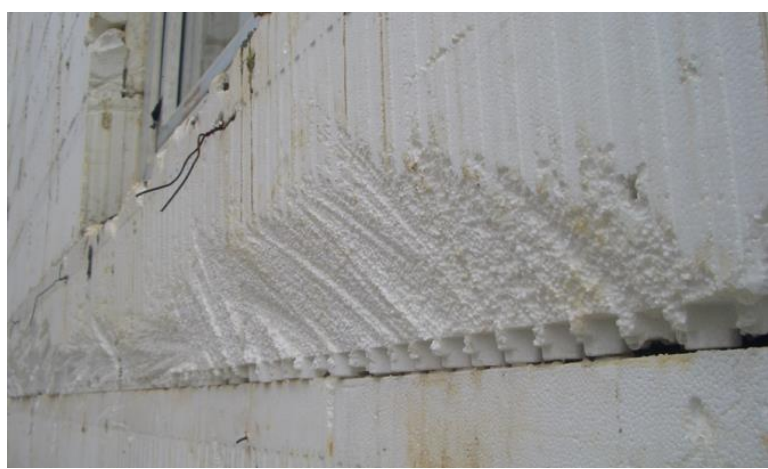

Fig. 4: Fragment of the outer wall with defect, "rectified" flush

It is known that heat-loss through the enclosing structure is largely dependent on the quality of construction work. Technological defects can lead to an increase in heat-loss of the building, despite the thoroughly justified design solutions. In this regard, the tasks of ensuring the quality of construction output are appropriate to consider together with the reliability of TS.

Currently, for the study of various aspects of reliability of TS, used in construction, a system of standards "Reliability in engineering" is used. In accordance with the Russian GOST 27.004-85, the technological system is a set of functionally related technological equipment, production objects and implementers to perform in the regulated conditions of production of the specified technological processes or operations.

Reliability of TS is a property of the system to perform a function to ensure the specified indexes of quality of construction output, productivity and economic efficiency in regulated conditions of construction works, storage and exploitation of technological equipment, storage and use of construction materials and structures, as well as the functioning of production and management personnel of relevant professions and qualifications. One of the directions of reliability assessment of construction TS is its definition on quality parameters of construction output. Analysis of the work log and defect statements found that the reliability of TS for quality parameters of cast-in-situ $\mathrm{RC}$ building construction in permanent EPS formwork largely depends on the structural solutions and on the method of concreting.

Divergences of formwork panels are caused by the rupture of ties on the actions of thrust forces from the placed and compacted concrete. During the inspection, it is found that the most frequent breaking of the tie rods occurs during the concreting by concrete pump. When using the concrete pump, production personnel allows the concreting with greater thickness than that provided in the technological chart. Furthermore, the material strength of the tie rod has a substantial importance. It was found that when concreting on the "cranebucket" scheme or by concrete pump the divergence 
of formwork panels is not observed at the steel tie rods. As part of the study, it is found that the rate of detected defects of permanent EPS formwork varies from 0.016 to 0.025 with an average value of 0.019 . The probability of assignment of quality parameters is an average of $P_{k j}=0.946$. By hypothesis of study the minimum value of fail-safe performance probability of TS is accepted $P_{\beta}=0.90$. Consequently, the said construction TS of cast-in-situ RC building construction in permanent EPS formwork can be characterized as corresponding to the specified level of reliability.

\section{Conclusion}

Cast-in-situ RC building construction in permanent EPS formwork is one of the most promising construction TS. High thermal-insulating and sound-absorbing properties of EPS allow using the formwork panels as the integral elements of constructed structures. Some non-critical defects occur during the functioning of TS. The most significant defects are formed as the divergences of formwork panels during the concreting. Improper resolve of these defects or hiding under a finishing layer can create the conditions for freezing of exterior walls during the cold season.

As a result of field study and analysis of defect statements it is found that TS of building construction in permanent EPS formwork is characterized by high reliability on quality parameters.

\section{References}

Abramyan SG, Akhmedov AM, Khalilov VS, and Umantsev DA (2014). Development of cast-in-situ construction and contemporary formwork systems. Vestnik Volgogradskogo Gosudarstvennogo Arkhitekturno-Stroitel'nogo Universi-teta. Series: Construction and Architecture, 36 (55): 231-239.

Badin GM (2012). Permanent formwork systems for exterior walls of low-rise buildings. Vestnik Grazhdanskikh Inzhenerov, 1: 137-142.

Baiburin AH (2015). Probability assessment of accident considering the errors of participants in the construction. Vestnik Yuzhno-Ural'skogo Gosudarstven-Nogo Universiteta. Series: Construction and Architecture, 15(1): 10-13.
Baiburin AH and Golovnev SG (2006). Quality and safety of construction technology: Monograph. Ural State Technical University, Chelyabinsk, Russia.

Derome D and Saneinejad S (2010). Inward vapor diffusion due to high temperature gradients in experimentally tested largescale wall assemblies. Building and Environment, 45(12): 2790-2797.

Fedyuk RS and Baranov VA (2015). Field investigations of humidity conditions of cast-in-situ walls with permanent EPS formwork. Vestnik Tikhookeanskogo Gosudarstvennogo Universiteta, 3: 151-158.

Havez AA, Wahab N, Al-Mayah A, and Soudki KA (2016). Behaviour of PVC encased reinforced concrete walls under eccentric axial loading. Structures, 5: 67-75.

Nazarko L (2015). Technology assessment in construction sector as a towards sustainability. Procedia Engineering, 122: 290295.

Nightingale P (2004). Technological capabilities, invisible infrastructure and the un-social construction of predictability: The overlooked fixed costs of useful research. Research Policy, 33(9): 1259-1284.

Ralston B and Osswald T (2008). Viscosity of soy protein plastics determined by screw-driven capillary rheometry. Journal of Polymers and the Environment, 16(3): 169-176.

Ryazanova GN and Kamburg VG (2010). Perfection of construction technology of enclosing structures in permanent formwork. Scientific Publication, Publishing House PGUAS, Penza, Russia.

Scott B, Wahab N, Al-Mayah A, and Soudki KA (2016). Effect of stay-in-place PVC formwork panel geometry on flexural behavior of reinforced concrete walls. Elsevier, 5: 123-130.

Soltani MM, Zhu Z, and Hammad A (2016). Automated annotation for visual recognition of construction resources using synthetic images. Automation in Construction, 62: 14-23.

Svintsov AP and Panin OV (2011). Reliability of the technological system of erection of cast-in-situ reinforced concrete walls. Vestnik RUDN, Engineering Studies, 2: 43-47.

VanderWerf PA (2007). The concrete house: Building solid, safe \& efficient with insulating concrete forms. Sterling Publishing Company, NewYork, USA.

Verbruggen S, Remy O, Wastiels J, and Tysmans T (2013). Stay-inplace formwork of TRC designed as shear reinforcement for concrete beams. Advances in Materials Science and Engineering. 2013: Article ID 648943, 9 pages. https://doi.org/10.1155/2013/648943

Verbruggen S, Tysmans T, and Wastiels J (2014). TRC or CFRP strengthening for reinforced concrete beams: An experimental study of the cracking behavior. Engineering Structures, 77: 49-56. 